\title{
Conceptual Correspondence Monitoring: Multimode Information Logistics Approach
}

\author{
Peteris Rudzajs and Marite Kirikova \\ Department of Systems Theory and Design, Faculty of Computer Science and Information Technology, Riga Technical \\ University, 1 Kalku, Riga, Latvia, LV-1658 \\ peteris.rudzajs@rtu.lv, marite.kirikova@cs.rtu.lv
}

\begin{abstract}
The paper addresses the problems arising in situations where conceptual correspondence has to be monitored, i.e., there are two or more structures of concepts which have a physical or abstract mapping and the changes in the structures of concepts may introduce the changes in the mapping. Usually the monitoring of conceptual correspondence requires manual, semiautomatic, and automatic information processing and exposes high level of complexity. The integration of different types of information processing units can be achieved by the use of multimode information logistics. The paper discusses challenges of the use of multimode information logistics in monitoring conceptual correspondence and proposes an approach that helps to partly meet the discussed challenges by jointly using functional and morphological spaces of representation of information logistics networks. The proposed approach is illustrated by an example of monitoring conceptual correspondence between knowledge demand and offer in the area of education.

Keywords: Multimode information logistics, monitoring services, conceptual correspondence, space of representation
\end{abstract}

\section{Introduction}

In contexts where information changes rapidly, the monitoring of information can be a necessary precondition for stating and fulfilling enterprise mission, strategy, and goals, and staying competitive in the business environment. Monitoring is "the act of observing something (and sometimes keeping a record of it)" [1]. The main purpose of monitoring is to provide the ability to observe a situation for any changes, which may occur over time. Basic functionality of monitoring includes gathering of source data, data processing, and data analysis for supporting decision-making by information according to particular metrics [2]. Usually monitoring concerns quantitative information. Recently the need to consider conceptual information has also been recognized [3], [4], [5]. Traditionally the sources of numerical data in monitoring are hard sensors or databases [6] and the data is usually handled by well defined algorithms. In case of conceptual information, more often than in cases of numerical data, the information may be handled by soft sensors and "processors" (human brain) [6]. Another important issue is the level of predictability in pre- and post-monitoring information logistics. In the case of conceptual information this level can be much lower than in the case of numerical information.

Information logistics [7] is a network of information processing entities (artificial, natural, or virtual nodes), which, acting in a particular order, form or execute a process that transforms a given input into a particular output. The input is a kind of fragmented information or knowledge description that is obtained from an information supplier or source. Input information can be 
handled manually, automatically, or semi-automatically. The process output is an information product that becomes accessible and may be delivered to the information receiver who can use the information. The basic functional ingredients of the information logistics process are supplying information, producing information, and distributing information. Information logistics aims to guarantee that information with good quality is produced and delivered to the 'customer' to the right place just in time [8]. Usually information logistics is considered from the point of view of organizational role-based information demand and/or offer in pre-defined internal and external organizational networks [7]. However, conceptual information may quite often be obtained from the emergent rather than pre-defined sources. For example, there are new scientific results, which might be included in the study program of a university: it is not possible to predict the time of emergence of the scientific discoveries and it is not possible to predict how exactly this information will reach the decision makers.

The goal of this paper is to propose an approach that is suitable for supporting information logistics in the situations where the following features are observed:

- The information logistics network can include emergent nodes (node here is a physical or virtual entity with the capacity to receive, process, and/or expose data, information, and/or knowledge)

- Information under consideration is mainly conceptual (non-numerical)

- At least one node in the network has the task to monitor the conceptual correspondence of information obtained from different sources

These situations have been scarcely investigated in the domain of information logistics. The contribution of the paper is the introduction of approach that is based on the use of functional and morphological spaces of representation and information codes to handle information logistics in the situations with abovementioned features. The paper adopts an understanding of information as a phenomenon that exists only at the moment when knowledge interprets the data, which has been perceived by the information processing entity (node) [9]. Thus, the knowledge of each information processing node as well as the availability of data are taken into consideration in the emergent information logistics network. Each node in the network is viewed as either (1) having hard sensors and different levels of artificial intelligence (including fully predefined processing) or (2) having soft sensors and human intelligence, or (3) a combination of both above-mentioned cases [6]. Our research process starts by considering the monitoring of the conceptual correspondence from the point of view of information logistics; then we describe information logistics in the functional and morphological spaces and introduce the information codes for information processing. Then we, for the illustration, represent information logistics of a knowledge demand and offer monitoring system EduMon in both spaces and discuss the challenges of multimode information logistics. The paper extends our previous work presented in [10] by incorporating richer set of examples and models.

The paper is structured as follows. In Section 2, the need for and approaches to the identification of conceptual correspondence are surveyed. In Section 3, the conceptual correspondence as a monitoring parameter is discussed and potential information logistics inside the monitoring node and around it is considered. In Section 4, the substance and the level of intelligence of nodes of information handling in the information logistics network are explained. In Section 5, the problems in multimode information logistics are discussed and some of their solutions are considered. In Section 6, brief conclusions are presented and further work is outlined. As mentioned above the issues discussed in the paper are illustrated by the examples of knowledge demand and offer correspondence monitoring system EduMon.

\section{Identification of the conceptual correspondence}

Monitoring of a particular parameter requires continuously observing its values according to the chosen method of data acquisition. The values of parameters can be obtained directly from the 
environment or calculated on the basis of values of other observable parameters. Conceptual correspondence cannot be observed directly. Therefore it is necessary to establish a certain information logistics to obtain and use the "value" of conceptual correspondence.

In this paper we define conceptual correspondence as an indicator of correspondence between two or more knowledge bodies (or parts of knowledge bodies). The knowledge bodies can be reflected in various information sources such as web pages, databases, electronic and nonelectronic documents, etc. Usually they are represented in natural language as unstructured or semi-structured texts [11].

Since the conceptual correspondence is the metrics that shows similarity between knowledge bodies, it cannot be detected just by keyword search or planar statistical text comparison methods. Conceptual correspondence is about the correspondence of meanings. Thus, it requires understanding the relationships between the concepts. The most usual evaluation mode of conceptual correspondence is the manual one where human experts detect the correspondence. For example, in the knowledge audit an auditor detects correspondence between the content of the study course and the SWEBOK (Software Engineering Body of Knowledge) [12]. Manual identification and understanding of texts is time-consuming. This causes the necessity to develop automated or semi-automated approaches and tools to reduce the time and effort required for identification of conceptual correspondence.

To identify the conceptual correspondence between various sources automatically or semiautomatically, information should be properly managed and processed. The key aspects to pay attention to in this task are (1) the identification and representation of information sources (knowledge bodies) that are to be compared and (2) the identification of changes in those sources over the time [13].

Since the relationships between the concepts play a major role in evaluation of conceptual correspondence, the conceptual structures should be derived from textual information (in some cases these structures are already given in the knowledge bodies e.g., in the form of the tree like structures of the basic terms of the knowledge body). Information in conceptual structures usually is organized in a meaningful way by using concepts and relationships between them (e.g., concept hierarchies and concept maps) or in a more formal way - in the form of ontologies [5], [6], [14], [15], [16], [17]. Information represented in the form of ontologies can be understood by humans and processed by computers. When conceptual structures are represented as ontologies a number of ontology matching techniques and tools can be used, e.g., the techniques described in [18]. There are also automatic conceptual structure comparison methods and tools that can be used in the cases when conceptual hierarchies or controlled dictionaries are available [19]. Interactive inductive learning methods are developed for comparison of conceptual structures in semi-automated mode [20].

From the point of view of information logistics there are different information logistics networks behind various methods of identification of conceptual correspondence. For example, the monitoring conceptual correspondence between two bodies of knowledge (texts), can include a flow of information from the sources of the texts to the points where ontologies corresponding to the texts are created; then from these points - to the ontology matcher tool [21]; then to the tool that can present the results in a meaningful way; and then to the users of obtained information about the conceptual correspondence between the bodies of knowledge (see Figure 1 A). In case the interactive inductive learning tool [20] is used in finding the conceptual correspondence, an information flow additionally exists from the expert(s) who prepare the learning example sets to the correspondence identification tool and information flows to and from the expert each time the tool requests the expert help (Figure $1 \mathrm{~B}$ ). 


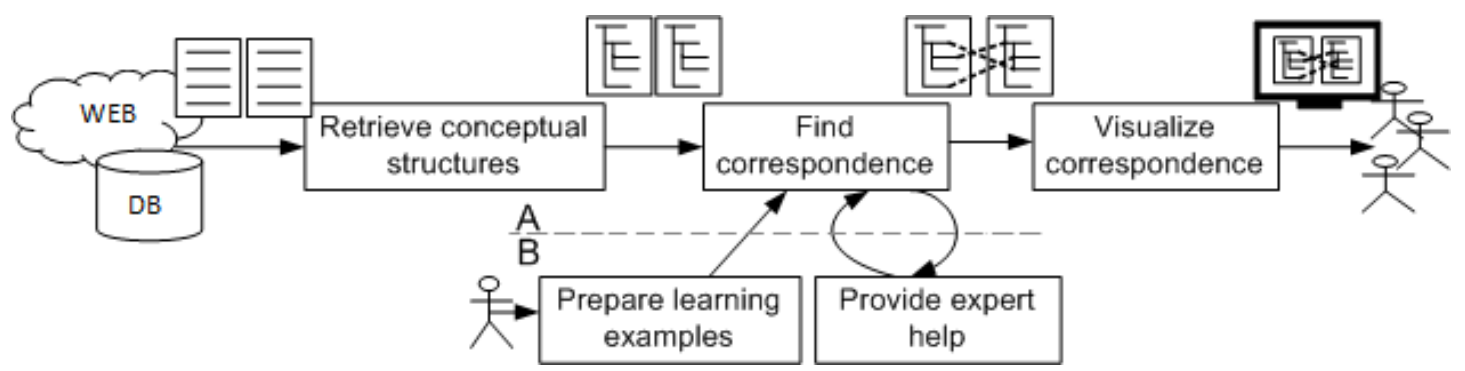

Figure 1. The dependence of information logistics on the method of conceptual correspondence identification

Thus, in monitoring conceptual correspondence, the method of identification of the correspondence predefines a particular information logistics network, which is a part of overall information logistics network.

\section{Monitoring of the conceptual correspondence}

Information logistics [7] is a network of information processing entities (artificial, natural, or virtual nodes), which, acting in a particular order, form or execute a process (further in the paper called "information logistics process") that transforms a given input into a particular output. On the one hand, the basic functions of the information logistics process are supplying information, producing information, and distributing information [8]. On the other hand, basic functionality of monitoring includes gathering of source data, data processing, and data analysis to provide decision support information [2] according to particular metrics. The monitoring process has all basic functions of the information logistics since supplying information corresponds to gathering of source data; producing information corresponds data processing and data analysis; and distributing information corresponds to providing decision support information. This lets to conclude that in the cases when one of the nodes of the information logistics network is a monitoring node, its structure will be a nested information logistics network. Therefore, in the remainder of the text we will refer to the internal and external information logistics with respect to the monitoring node, which performs the function of the monitoring. In the upper part of Figure 2 functions outside Monitoring Function belong to the external information logistics and functions inside Monitoring Function belong to the internal information logistics; and on a higher level of abstraction Monitoring Function itself fulfills the function of information

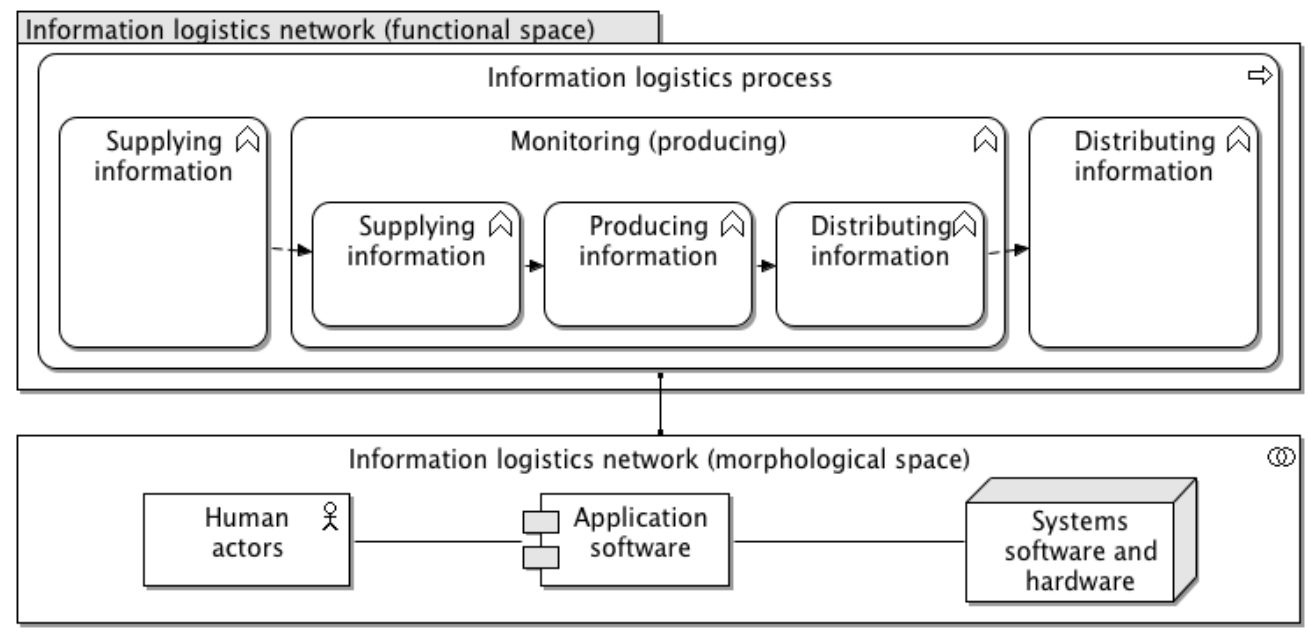

Figure 2. Monitoring node as a nested information logistics network (functional space of representation) and information logistics in the morphological space of representation. 
production in the information logistics network.

Information logistics can be defined in the functional space where in the logistics network each node is a function (upper part of Figure 2). It can be also defined in the morphological space where each node of the network is a particular agent or object that handles the information [22], [23] (lower part of Figure 2). Icons in Figure 2 are borrowed from ArchiMate 2.0 [24], however the meaning of colors prescribed by ArchiMate 2.0 is not taken into consideration.

In this section information logistics is described in the functional space of representation. In the next section the morphological space of representation is considered.

Functions in the functional space can be interpreted as services that fulfill a particular functional need (internal or external to the enterprise or artificial system) and provide a unit of functionality that is meaningful from the point of view of the environment. Thus, in functional space of information logistics, the functional units form a particular network according to their actual involvement in information processing. Further in the paper we use an example of EduMon [25] system to illustrate information logistics network and its functional units. EduMon system is designed for monitoring correspondence between the industrial knowledge need and the educational knowledge offer provided by universities study programs. At a high level of abstraction the functionality of this system can be considered as a monitoring node in the functional space of information logistics for conceptual correspondence monitoring. Thus, the internal information logistics of the monitoring node can be defined by configurations of the following classes of services (i.e. functional units) forming the EduMon architecture [25]:

- Class 1: information source management services (SoMS)

- Class 2: information retrieval services (IRS)

- Class 3: information extraction services (IES)

- Class 4: change management services (ChMS)

- Class 5: storage management services (SMS)

- Class 6: analysis services (AS)

- Class 7: notification services (NS)

- Class 8: presentation services (PS)

These services can be described according to the basic functions of the monitoring node presented in Figure 3 (monitoring node as a part of information logistics process is represented in Figure 2):

- Supplying function is responsible for identification of information sources in the monitoring environment. Monitoring environment here refers to all functions that can be related to, but do not belong to EduMon system. In EduMon system the supplying function is performed by services of Class 1 .

- Producing function processes all source information gathered from monitoring environment. In EduMon system this function aims at extraction of concepts and generation of conceptual structures (hierarchical or in the form of ontologies). These generated conceptual structures can be compared and their correspondence identified. The producing function in EduMon system is performed by services of Classes 2-6.

- Distributing function distributes the information about correspondence between conceptual structures to other nodes such as functions performed by communication portal and information consumers of the EduMon System. The distributing function here refers to Services of Class 7 and Class 8.

Depending on the physical performer of the services, each function and service at any level of the representational granularity can be performed manually, semi-automatically, or automatically. This requires considering all three modes of information handling in the 


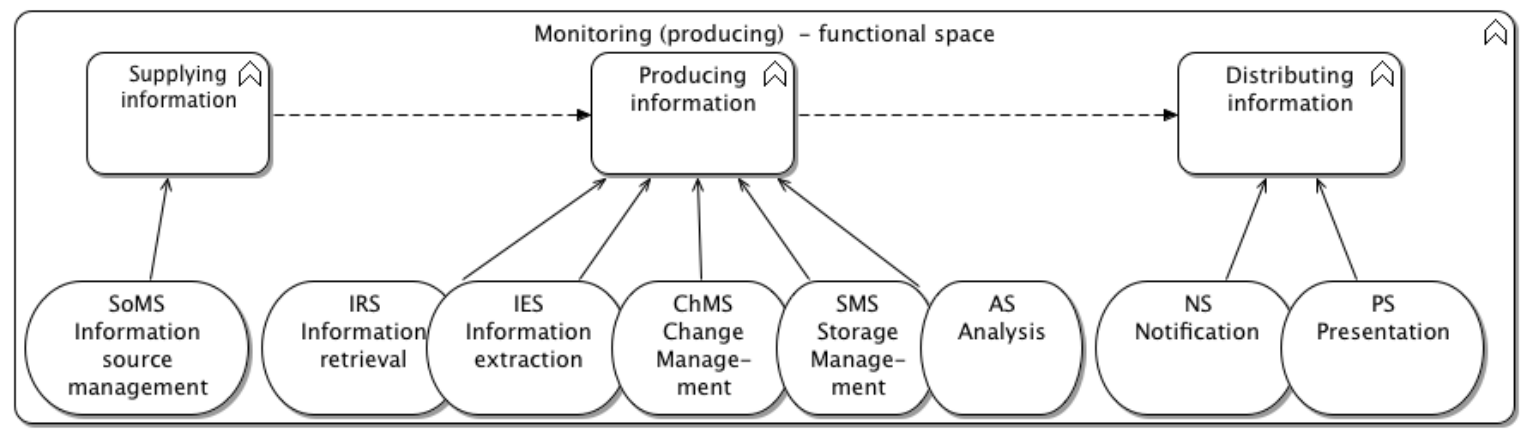

Figure 3. Internal information logistics of monitoring node and corresponding EduMon services information logistics for conceptual correspondence monitoring.

\section{The modes of information handling}

In the functional space of representation we pay attention only to the transformation and transfer of data, information, and knowledge. Thus the network in this space looks like a data flow diagram, where inputs and outputs of one function can be outputs and inputs of other functions. The functions can be considered internally and externally from the point of view of particular systems, which they belong to or are used by (Figure 3). Thus functions at one level of abstraction may belong to services at another level of abstraction and services at a particular level of abstraction may contain functions, which can be represented at lower levels of abstraction. Figuratively services perform functions, since they denote the transformation of information. Thus there is a service-function dichotomy in the functional space of representation. Physically functions and services are performed by information processing nodes (IPNs), human beings or artificial information handling entities such as software and computers. The type of physical performer has to be taken into consideration if we want to distinguish between different modes of information processing in the functional space of representation. Therefore it is necessary to use the morphological space of representation additionally to the above-described functional space of representation.

In the functional space of representation the nodes of the information logistics network are functions or services. In the morphological space of representation the nodes of the information logistics network are IPNs with a particular built-in or obtained knowledge and particular levels of intelligence. With respect to conceptual information handling, both human and artificial intelligence can be a property of the nodes included or emerging in the network.

In the context of meaningful information processing the knowledge processes the information. This statement is partly adopted from the research works on information codes [26], [27]. According to this view on the information processing, we can assume that in the information logistics network information is circulated using so called information codes. These codes can be perceived by IPNs (the nodes of information logistics network) having the perceptional capability. The nodes use their knowledge to obtain data from the information codes and with the help of their knowledge interpret the data and obtain the information (if a particular node has an information interpretation capability) (see illustration in Figure 4) [9]. IPNs with an appropriate level of intelligence can incorporate the obtained information in their knowledge and make new interpretations of pieces of their knowledge with the purpose to propagate the information codes to other IPNs.

Thus each function or service represented in the functional space can be related to one or several IPNs represented in the morphological space and vice versa. Table 1 presents different information handling possibilities in the morphological space of information logistics. $D$ in the table stays for data, $K$ stays for knowledge intended to be propagated, $\mathrm{K}$ ' stays for knowledge 
obtained by the node ( $\mathrm{K}^{\prime}$ is not the same as $\left.\mathrm{K}\right), I$ - information as intended, I' - information that differs from the intended one (it refers to the cases where the receiving node interprets the data differently if to compare to the node having initiated the information exchange). HIPN stays for human information processing node; AIPN stays for artificial information processing node. Each cell in the table represents all possible information code flows between two IPNs. Only IPNs having transmission capability are included into the table.

In Table 1 we can see different ways how data, information, and knowledge can be shared and received (or taken in) depending on the nature of sharer and receiver. Any sequence $X \rightarrow Y$ between the nodes (where X can be D, I, or K and Y can be D, I, I', K, or K') may be regarded as particular flow of at least one of the following phenomena: (1) data, (2) information, and (3) knowledge; which are represented by information codes. HIPN can deal with all three

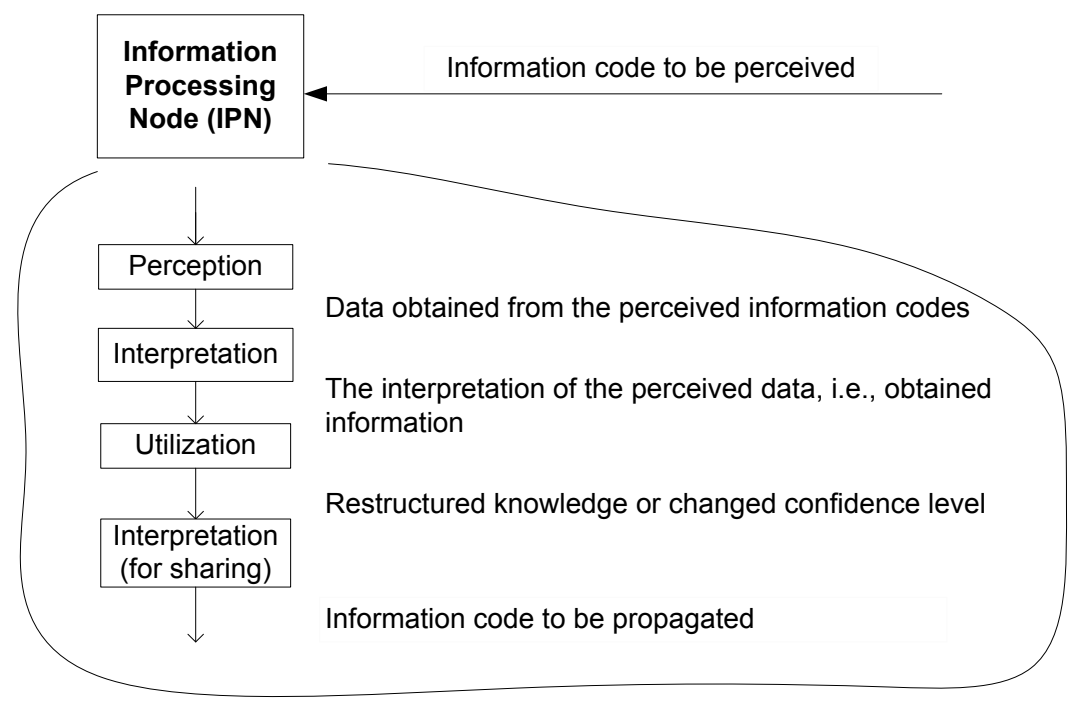

Figure 4. Inside the information processing node

phenomena while different artificial nodes can be restricted to data only, and data and information only. All three types of AIPNs can deal with artificial knowledge only [28].

Table 1. Information handling capabilities of IPNs

\begin{tabular}{|c|c|c|c|c|}
\hline Node & HIPN & $\begin{array}{l}\text { AIPN } \\
\text { transmitter }\end{array}$ & $\begin{array}{l}\text { AIPN } \\
\text { Transmitterl } \\
\text { saverl } \\
\text { transformer }\end{array}$ & $\begin{array}{l}\text { AIPN } \\
\text { Transmitterl } \\
\text { transformerl } \\
\text { saver/learner }\end{array}$ \\
\hline HIPN & $\begin{array}{l}\mathrm{D} \rightarrow \mathrm{D}, \mathrm{I}^{\prime}, \mathrm{K}^{\prime} \\
\mathrm{I} \rightarrow \mathrm{D}, \mathrm{I}, \mathrm{I}^{\prime} \mathrm{K}^{\prime} \\
\mathrm{K} \rightarrow \mathrm{D}, \mathrm{I}, \mathrm{I}^{\prime} \mathrm{K}, \mathrm{K}^{\prime}\end{array}$ & $\begin{array}{l}\mathrm{D} \rightarrow \mathrm{D} \\
\mathrm{l} \rightarrow \mathrm{D} \\
\mathrm{K} \rightarrow \mathrm{D}\end{array}$ & $\begin{array}{l}\mathrm{D} \rightarrow \mathrm{I}^{\prime} \\
\mathrm{I} \rightarrow \mathrm{I}, \mathrm{I}^{\prime} \\
\mathrm{K} \rightarrow \mathrm{l}, \mathrm{I}^{\prime}\end{array}$ & $\begin{array}{l}\mathrm{D} \rightarrow \mathrm{D}, \mathrm{I}^{\prime}, \mathrm{K}^{\prime} \\
\mathrm{I} \rightarrow \mathrm{D}, \mathrm{I}, \mathrm{I}^{\prime} \mathrm{K}^{\prime} \\
\mathrm{K} \rightarrow \mathrm{D}, \mathrm{I}, \mathrm{I}^{\prime} \mathrm{K}, \mathrm{K}^{\prime}\end{array}$ \\
\hline $\begin{array}{l}\text { AlPN } \\
\text { Transmitter }\end{array}$ & $\mathrm{D} \rightarrow \mathrm{D}, \mathrm{I}^{\prime}, \mathrm{K}^{\prime}$ & $\mathrm{D} \rightarrow \mathrm{D}$ & $\mathrm{D} \rightarrow \mathrm{I}^{\prime}$ & $\mathrm{D} \rightarrow \mathrm{D}, \mathrm{I}^{\prime}, \mathrm{K}^{\prime}$ \\
\hline $\begin{array}{l}\text { AIPN } \\
\text { Transmitter/saver/ } \\
\text { Transformer }\end{array}$ & $\begin{array}{l}D \rightarrow D, I^{\prime}, K^{\prime} \\
I \rightarrow D, I, I^{\prime} K^{\prime}\end{array}$ & $\begin{array}{l}\mathrm{D} \rightarrow \mathrm{D} \\
\mathrm{l} \rightarrow \mathrm{D}\end{array}$ & $\begin{array}{l}\mathrm{D} \rightarrow \mathrm{I}^{\prime} \\
\mathrm{I} \rightarrow \mathrm{I}, \mathrm{I}^{\prime}\end{array}$ & $\begin{array}{l}D \rightarrow D, I^{\prime}, K^{\prime} \\
I \rightarrow D, I, I^{\prime} K^{\prime}\end{array}$ \\
\hline $\begin{array}{l}\text { AlPN } \\
\text { Transmitter/saver/ } \\
\text { Transformer/learner }\end{array}$ & $\begin{array}{l}\mathrm{D} \rightarrow \mathrm{D}, \mathrm{I}^{\prime}, \mathrm{K}^{\prime} \\
\mathrm{I} \rightarrow \mathrm{D}, \mathrm{I}, \mathrm{I}^{\prime} \mathrm{K}^{\prime} \\
\mathrm{K} \rightarrow \mathrm{D}, \mathrm{I}, \mathrm{I}^{\prime} \mathrm{K}, \mathrm{K}^{\prime}\end{array}$ & $\begin{array}{l}\mathrm{D} \rightarrow \mathrm{D} \\
\mathrm{l} \rightarrow \mathrm{D} \\
\mathrm{K} \rightarrow \mathrm{D}\end{array}$ & $\begin{array}{l}\mathrm{D} \rightarrow \mathrm{I}^{\prime} \\
\mathrm{l} \rightarrow \mathrm{I}, \mathrm{I}^{\prime} \\
\mathrm{K} \rightarrow \mathrm{I}, \mathrm{I}^{\prime}\end{array}$ & $\begin{array}{l}\mathrm{D} \rightarrow \mathrm{D}, \mathrm{I}^{\prime}, \mathrm{K}^{\prime} \\
\mathrm{I} \rightarrow \mathrm{D}, \mathrm{I}, \mathrm{I}^{\prime} \mathrm{K} \\
\mathrm{K} \rightarrow \mathrm{D}, \mathrm{I}, \mathrm{I}^{\prime} \mathrm{K}, \mathrm{K}^{\prime}\end{array}$ \\
\hline
\end{tabular}

Concerning artificial nodes (AIPNs) of the information logistics network, the following cases of information handling capability have to be considered (see Figure 5): 
- AIPN as transmitter only - the node, that can only perceive the information codes and make them available for other nodes without meaningful interpretation; the only available product from this type of nodes is data that can be propagated to other nodes of the network.

- AIPN as a transmitter and saver and/or transformer of information. In this case artificial information handling node can save and/or transform the information which it is able to perceive (e.g., DBMS with data). In this case the interpretation mechanism is built in the node and resembles the knowledge of programmer of the node rather than the knowledge of the node itself; still the node can produce data as well as information. This IPN does not change the structure of the frame of knowledge (or data), which it uses for information processing.

- AIPN as a transmitter and saver and/or transformer of information, and/or learner. This IPN has all capabilities listed in the previous point and additionally it can learn from its own "experience", i.e., it has a measure of artificial intelligence that can be built-in, acquired, and extended during the process of information processing.

Human information processing and artificial information processing relevant in morphological space of information logistics representation should also be considered in the functional space of information logistics representation. The functions may be handled in various modes depending on the elements (or their networked combinations) of the morphological space, which are taking part in fulfillment of particular functions represented in the functional space. The functions can be accomplished manually (HIPNs only are involved), automatically (AIPNs are involved), or semi-automatically (HIPNs and AIPNs are involved). These modes are represented in Figure 6 where they group particular types of IPNs (see Figure 5).

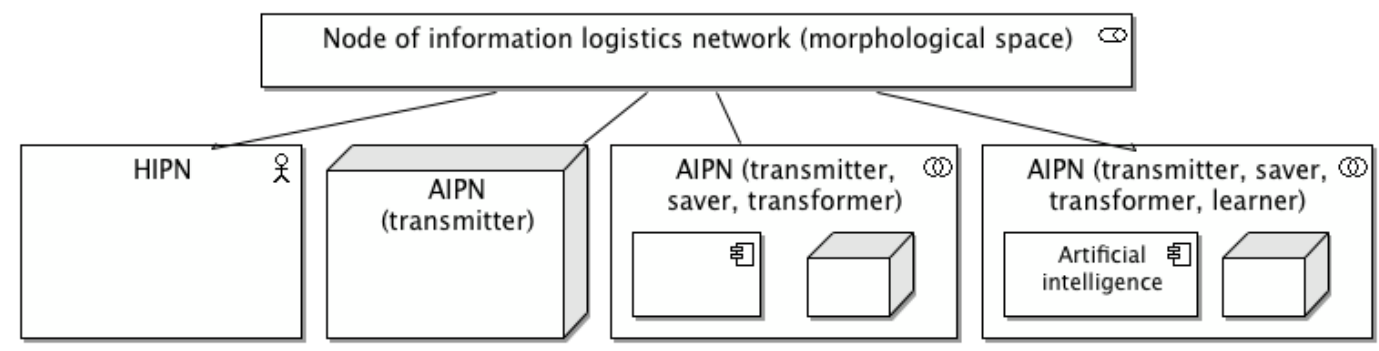

Figure 5. Types of nodes of information processing (morphological space)

Taking into consideration that there can be nested nodes in both representational spaces, different spectrums of information handling modes at different levels of granularity may be observed. The more diverse the spectrum, the more complex is the overall information processing, because particular interfaces between the nodes considered in the morphological space have to be established to ensure that in the functional space an information code provided by a particular functional node in a particular mode of performance is perceivable by another functional node for all possible modes of performance. In Table 2 the variations of information handling modes of the monitoring node described in Section 3 are given at the highest level of functional granularity. All three basic functions of the monitoring node, namely, supplying, processing, and distributing (see the upper part of Figure 2), can be performed in manual, automatic and semi-automatic modes, so it means that in the morphological space there are 27 alternatives how the monitoring node can be configured and executed in the information logistics network (see Table 2; similar table of service modes is discussed in [13]). Practical example of EduMon system considering different information handling modes is given in Figure 8 and Figure 9. 


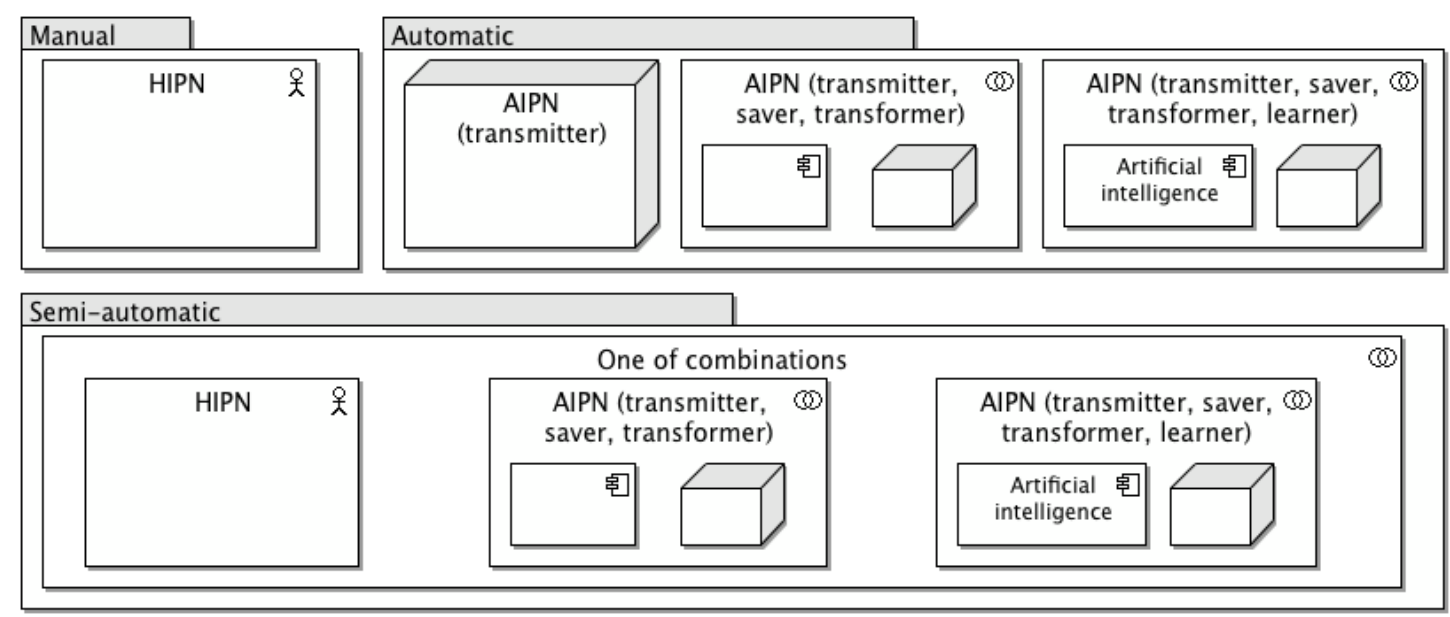

Figure 6. Modes of information processing, grouping the types of IPNs participating in accomplishment of functions

Table 2 represents the complexity of internal logistics of the monitoring node. It has to be taken into consideration that the monitoring node is related to other nodes in its external logistics network. Some of these relationships in morphological space are illustrated for EduMon system in Figure 7.

Full complexity of multimode information logistics is seen when the combinations of internal and external networks of logistics for monitoring of conceptual correspondence are considered, including the acknowledgment of the fact that both types of networks can include emergent IPNs and functions, which can require any modes of information handling.

Table 2. Monitoring node configuration options. (Rows - information transmitted from; columns - information transmitted to). For example - if supplying is handled manually (M) and processing - semi automatically (SA), then distributing function can be still handled manually (M), automatically (A), or semi-automatically (SA) (see the text with grey background). For practical example see Figure 8 and Figure 9.

\begin{tabular}{|c|c|l|l|}
\hline & Supplying & Processing & Distributing \\
\hline Supplying & - & $\begin{array}{l}\text { M-M, M-SA, M-A } \\
\text { SA-M, SA-A, SA-SA } \\
\text { A-A, A-M, A-SA }\end{array}$ & - \\
\hline Processing & - & - & $\begin{array}{l}\text { M-M, M-SA, M-A } \\
\text { SA-M, SA-A, SA-SA } \\
\text { A-A, A-M, A-SA }\end{array}$ \\
\hline Distributing & - & - & - \\
\hline
\end{tabular}

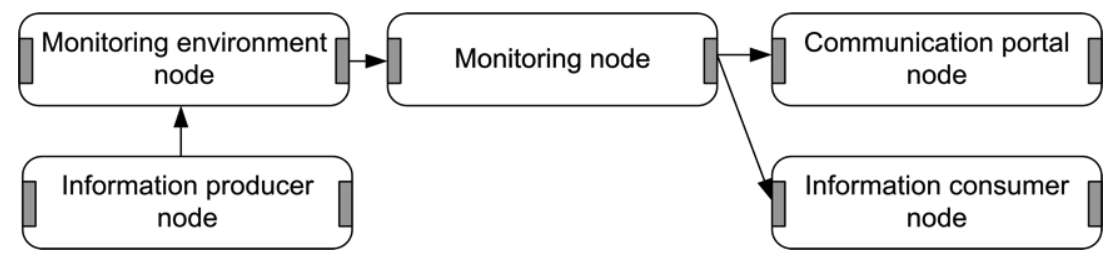

Figure 7. External network of the monitoring node (morphological space of information logistics); it is assumed that the monitoring node in the morphological space includes all IPNs that participate in fulfillment of its functions represented in the functional space of information logistics 


\section{Challenges of multimode information logistics}

As discussed in previous sections, monitoring of conceptual correspondence requires the use of multimode information logistics. This means that theoretically any connection between information processing functions can be implemented in different combinations (see column 2 in Table 2). Obviously, not all of these combinations are relevant in reality. Still there is a high complexity of information handling in situations of multimode information logistics. One of the ways to cope with this complexity is to distinguish between the functional and morphological spaces of representation. This is illustrated in Figure 8 and Figure 9 by simplified EduMon system (see more details in Section 3) serving as a monitoring node in the information logistics network. In Figure 8 and Figure 9 one node in the morphological space of representation corresponds to one node in the functional space of representation. In real situations many-tomany relationships may exist between the nodes at different representational levels; nevertheless, knowing, which nodes of the morphological space participate in which functions of the functional space, can help to develop artificial IPNs and to manage the information logistics network. The abbreviations used in Figure 8 and Figure 9 are described in Section 3 and Section 4.

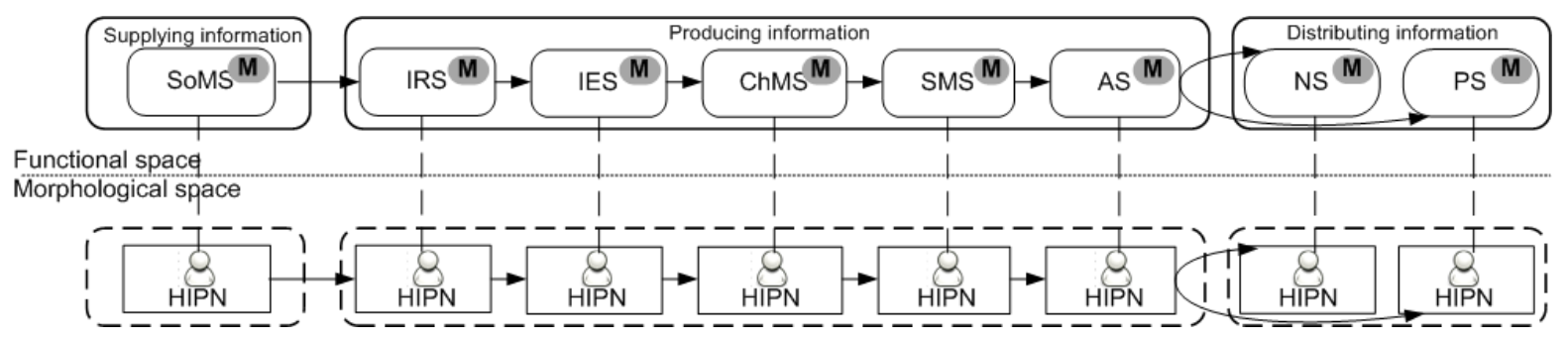

Figure 8. Single-mode logistics as a specific case of a multimode information logistics; HIPNs should be considered here as different information processing roles [7] that can be performed by a random number of performers

In Figure 8 we can see a specific case of information logistics where all functions are performed manually. In this case there is only one interface option and the actual use of the interface can be negotiated, i.e., it is not mandatory to strictly specify how to use the interface. Thus, at least theoretically, it can be relatively easy to handle the emergent nodes in the network. The situation becomes more complex when different types of IPNs are involved in information processing (see Figure 9).

Only two of various possible information logistics configurations of EduMon monitoring node internal logistics are shown in Figure 8 and Figure 9. To ensure that the results of functioning of the monitoring node are always meaningful and reach the "customers" of information, it is necessary to ensure that all possible functioning modes for all relevant network configurations are supported. This includes handling of emergent nodes in external and internal information logistics networks of the monitoring node in both spaces of representation. Emergent nodes in the morphological space can be connected to the information logistics network on their own initiative or in the result of activities of human actors or artificial agents searching for relevant nodes [13]. In handling above mentioned complexity, it is important to consider granularity of representation, especially in cases of emergent IPNs and corresponding emergent functions. It is also necessary to acknowledge all possible variations of connections at all levels of granularity, each of which can invoke multiple modes of functioning. It is essential that the smallest level of granularity of representation in the functional space would correspond to the actual activity of an emergent node represented in the morphological space. 


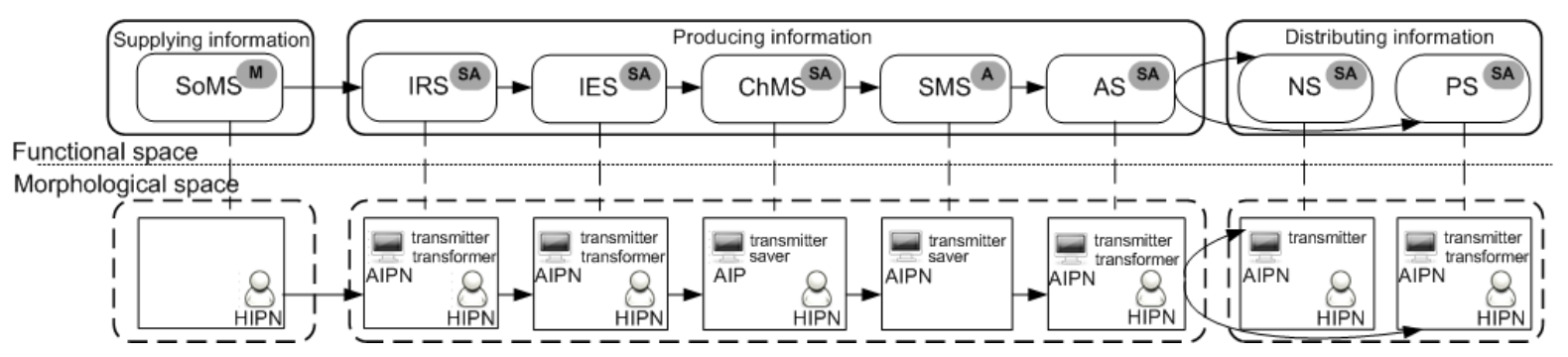

Figure 9. Multimode logistics (simplified: the relationships between multiple sub-elements of the nodes are not shown in the morphological space of representation)

To some extent we can illustrate the real complexity of information logistics in conceptual correspondence monitoring by EduMon example where correspondence between university study courses and software engineering body of knowledge SWEBOK [12] is monitored (this example relates to general conceptual correspondence identification illustrated in Figure 1). Here we (1) consider two selected information logistics configurations of EduMon internal logistics, which correspond to Figure 8 and Figure 9 and (2) comment on emergent nodes of monitoring node's external logistics. EduMon services correspond to the functions in the functional space of representation. Abstract performers of the services are considered in the morphological space of representation. In the morphological space the sub-columns with $F$ refer to the type of functioning mode (manual, semi-automatic, automatic) imposed by different types of IPNs to the nodes of functional space of representation. In Table 3 two information logistics scenarios are described. The second main column represents the single-mode scenario, where all the services are performed manually (see M in column F). The third main column represents one multi-mode scenario, where the services are executed manually, automatically, or semi-automatically $(\mathrm{M}, \mathrm{A}$, and SA in column F respectively).

EduMon services are listed in the rows of the first main column of Table 3. In case of SoMS, which is responsible for obtaining the information about the location of the information sources, we assume that sources of information are available on the Web. Regarding the functional mode of services we denote here by "manual" any human actor activity that does not use dedicated EduMon system's software.

Thus manual functioning mode does not exclude the use of such electronic tools as text editors (e.g., MS Word) and spreadsheets for information storage and processing. For example, in Table 3 in case of SoMS, in single- and multi-mode cases storage of data about monitoring information sources is performed manually by visiting Web and finding URLs to SWEBOK and curricula courses. However, the storage of URLs may be different - the information can be stored either electronically (simple text documents or specialized storage in EduMon database) or on the paper as hand-written or printed information. Automatic mode of SoMS service is possible only when new URLs (of, e.g., new courses or other knowledge bodies) are discovered in Web by a specific software tools (e.g., Web crawlers [29]) without participation of human actors.

$I R S$ is responsible for retrieving documents from stored URLs (see Row 2 in Table 3). If IRS is preformed semi-automatically, two IPNs are involved: (1) AIPN retrieves SWEBOK document and course description documents from defined URLs and (2) after retrieval, human actor (HIPN) checks if the content of retrieved documents is useful, since the situations occur when URLs are not available anymore due to the relocation of documents and so senseless document descriptions may be obtained. When necessary documents are retrieved, proper keywords and concept hierarchies should be extracted from the documents (see row IES in Table 3 and the fragment from SWEBOK concept hierarchy in Figure 10). Keywords should be extracted to simplify further processing of information, since it is easier to work with the list of keywords (or concept hierarchies) than with long texts. The extraction process, performed manually, is time consuming and error prone due to large volumes of documents to be processed. Semi-automatic 
mode can be more efficient as in this mode we can automatically extract relevant keywords and concepts from documents on the basis of already available concept hierarchies or dictionaries.

Table 3. Example of the scenarios of internal information logistics of monitoring node in case of monitoring the conceptual correspondence between SWEBOK and curricula courses

\begin{tabular}{|c|c|c|c|c|c|c|c|}
\hline \multicolumn{2}{|r|}{ Functional space } & \multirow{2}{*}{$\mathbf{F}}$. & \multicolumn{2}{|r|}{ Morphological space (single-mode) } & \multirow{2}{*}{$\begin{array}{l}\mathbf{F} . \\
\Sigma\end{array}$} & \multicolumn{2}{|c|}{$\begin{array}{c}\text { Morphological space } \\
\text { (multi-mode) }\end{array}$} \\
\hline$\sum_{0}^{\infty}$ & $\begin{array}{l}\text { Store information about } \\
\text { information sources }\end{array}$ & & $\frac{\underline{\underline{I}}}{\bar{x}}$ & $\begin{array}{l}\text { Visit Web and find URLs for } \\
\text { SWEBOK and courses of interest } \\
\text { (e.g. curricula courses). Store the } \\
\text { URLs in electronic or paper format } \\
\text { for the further reference }\end{array}$ & & 䱏 & $\begin{array}{l}\text { Visit Web and find URLs for } \\
\text { SWEBOK and courses of } \\
\text { interest (e.g. curricula courses). } \\
\text { Store the URLs in electronic } \\
\text { format for the further reference } \\
\text { (e.g., store in EduMon } \\
\text { database) }\end{array}$ \\
\hline $\begin{array}{l}\boldsymbol{\mathscr { D }} \\
\underline{\underline{u}}\end{array}$ & $\begin{array}{l}\text { Retrieve documents form } \\
\text { defined URLs }\end{array}$ & $\Sigma$ & $\frac{\varrho}{\bar{I}}$ & $\begin{array}{l}\text { Visit the URLs acquired earlier and } \\
\text { download the SWEBOK document } \\
\text { and course description documents }\end{array}$ & હ & $\begin{array}{l}\frac{0}{\bar{T}} \\
\frac{a}{\alpha}\end{array}$ & $\begin{array}{c}\text { Automatically retrieve } \\
\text { SWEBOK document and } \\
\text { course description documents } \\
\text { from defined URLs acquired } \\
\text { earlier. Human actor should } \\
\text { check if the content of retrieved } \\
\text { documents is as expected } \\
\end{array}$ \\
\hline 邑 & $\begin{array}{l}\text { Extract keywords (and/or } \\
\text { hierarchical representation of } \\
\text { concepts) from documents }\end{array}$ & $\Sigma$ & $\frac{\varrho}{\bar{I}}$ & $\begin{array}{c}\text { Read the SWEBOK document and } \\
\text { note the concept hierarchies; Note } \\
\text { the main keywords from course } \\
\text { description }\end{array}$ & ふ & $\begin{array}{l}\frac{0}{\bar{x}} \\
\frac{0}{\alpha}\end{array}$ & $\begin{array}{l}\text { With the help of human actor } \\
\text { extract the concept hierarchies } \\
\text { from SWEBOK. Based on } \\
\text { SWEBOK (and other } \\
\text { knowledge bodies already } \\
\text { existing in EduMon) } \\
\text { automatically extract the } \\
\text { keywords from course } \\
\text { description }\end{array}$ \\
\hline 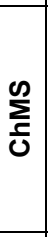 & $\begin{array}{c}\text { Identify the differences between } \\
\text { new and earlier obtained } \\
\text { concept hierarchies and } \\
\text { keywords. }\end{array}$ & $\Sigma$ & 高 & $\begin{array}{c}\text { Reread and compare new and } \\
\text { previous versions of SWEBOK } \\
\text { concept hierarchies and course } \\
\text { keywords }\end{array}$ & ๘ & $\begin{array}{l}\frac{0}{1} \\
\frac{a}{<}\end{array}$ & $\begin{array}{c}\text { Automatically check the } \\
\text { SWEBOK concept hierarchies } \\
\text { and course keywords for any } \\
\text { changes } \\
\text { (new/updated/deleted). Human } \\
\text { actor should verify the } \\
\text { identified changes. }\end{array}$ \\
\hline$\sum_{\infty}^{\infty}$ & $\begin{array}{l}\text { Store new concept hierarchies } \\
\text { and the identified changes }\end{array}$ & $\Sigma$ & 呈 & $\begin{array}{l}\text { Store the new concept hierarchies } \\
\text { and keywords and the changes } \\
\text { electronically or on the paper }\end{array}$ & $\varangle$ & $\frac{a}{\alpha}$ & $\begin{array}{c}\text { New concept hierarchies and } \\
\text { keywords and verified changes } \\
\text { are automatically stored in } \\
\text { EduMon system for further } \\
\text { reference by ChMS and AS } \\
\text { services } \\
\end{array}$ \\
\hline 里 & $\begin{array}{l}\text { Analyze the conceptual } \\
\text { correspondence }\end{array}$ & $\Sigma$ & 高 & $\begin{array}{c}\text { Read the course descriptions and } \\
\text { try to find if some of the course } \\
\text { keywords could be found in } \\
\text { SWEBOK }\end{array}$ & ふ & $\begin{array}{l}\frac{0}{\bar{x}} \\
\frac{0}{<}\end{array}$ & $\begin{array}{c}\text { Automatically identify } \\
\text { conceptual correspondence } \\
\text { between SWEBOK and } \\
\text { courses by linking SWEBOK } \\
\text { concepts to keywords available } \\
\text { in course descriptions. } \\
\text { Human actors should review } \\
\text { and verify the identified } \\
\text { correspondence. }\end{array}$ \\
\hline $\mathbf{n}$ & $\begin{array}{l}\text { Notify about information source } \\
\text { changes, or conceptual } \\
\text { correspondence changes }\end{array}$ & $\Sigma$ & 䱏 & $\begin{array}{l}\text { If some new correspondence are } \\
\text { found, e.g., some new topic } \\
\text { appeared in course that is also } \\
\text { included in SWEBOK, then the } \\
\text { decision is made whether to notify } \\
\text { some involved parties or not }\end{array}$ & ๘ & $\begin{array}{l}\frac{0}{1} \\
\frac{0}{\alpha}\end{array}$ & $\begin{array}{l}\text { EduMon system can be } \\
\text { configured to notify involved } \\
\text { parties about any SWEBOK } \\
\text { and/or course description } \\
\text { changes; about newly } \\
\text { discovered conceptual } \\
\text { correspondence, etc. } \\
\end{array}$ \\
\hline $\boldsymbol{\infty}$ & $\begin{array}{l}\text { Visualize conceptual } \\
\text { correspondence }\end{array}$ & $\Sigma$ & 高 & $\begin{array}{l}\text { Using some information processing } \\
\text { tool try to visualize conceptual } \\
\text { correspondence between } \\
\text { SWEBOK and curricula courses, } \\
\text { e.g. courses covering/not covering } \\
\text { some SWEBOK topics }\end{array}$ & હ & $\begin{array}{l}\frac{0}{\bar{T}} \\
\frac{a}{<}\end{array}$ & $\begin{array}{c}\text { EduMon system will provide } \\
\text { conceptual correspondence } \\
\text { visualization features; multiple } \\
\text { views could be available for } \\
\text { human actors. }\end{array}$ \\
\hline
\end{tabular}




\section{REQUIREMENTS ^}

1. Software Requirements Fundamentals

1.1. Definition of a Software Requirement

At its most basic, a software requirement is a property which must be ext "software" because it is concerned with problems to be addressed by si developed or adapted to solve a particular problem. The problem may b processes of the organization that has commissioned the software, to corr users, business processes, and devices is typically complex. By extensio requirements from different people at different levels of an organization a

An essential property of all software requirements is that they be veri verification of the throughput requirement on the call center may necess quality personnel must ensure that the requirements can be verified withir

Requirements have other attributes in addition to the behavioral properti face of finite resources and a status value to enable project progress to b the entire software life cycle. [Kot00; Pfl01; Som05; Tha97]

1.2. Product and Process Requirements

A distinction can be drawn between product parameters and process pa
Software Requirements

..Software Requirements Fundamentals

....Definition of a Software Requirement

....Product and Process Requirements

......product parameters

.......process parameters

....Functional and Nonfunctional Requirements

.......Functional requirements

.......Nonfunctional requirements

....Emergent Properties

....Quantifiable Requirements

....System Requirements and Software Requirements

$\rightarrow \quad$..Requirements Process

Figure 10. Extracted concept hierarchy (on the right) of SWEBOK source document (on the left) (relates to the "Retrieve conceptual structures" process illustrated in Figure 1)

$A S$ is responsible for analysis of conceptual correspondence between SWEBOK and curricula courses. The results of the analysis can become available for information visualization tools. Using these tools we can further analyze, e.g., correspondence between SWEBOK concepts and different courses of a particular curriculum (see Table 4) or the correspondence between the contents of a particular course and SWEBOK (see Table 5).

Table 4. Example of SWBOK concept "prototyping" correspondence to courses of curriculum "Computer Systems"

Software Requirements-->Requirements Validation-->Prototyping

Adaptive Data Processing Systems

Applied System Software

Fundamentals of Computer Systems Design

Applied Intelligent Systems

Architecture-Oriented Systems Development (Study Project)

Bachelor Thesis

To ensure continuous curricula course compliance with SWEBOK, the information logistics sequence represented in Table 3 should be performed periodically anticipating (by ChMS and NS; see corresponding rows in Table 3 ) the changes that may occur both in the new versions of SWEBOK and in the course descriptions.

Each service reflected in Table 3 can be performed manually, semi-automatically, or automatically. Figure 11 exposes the variations of functional modes of the first three services listed in Table 3. The same applies to other EduMon services. The option of network configuration that corresponds to Figure 9 is shown by the dotted lines in Figure 11. Particular mode of one service shall produce information in the format, which gives an opportunity to distribute it to other related services. 
Table 5. Example of correspondence between course "Software Engineering" and SWEBOK
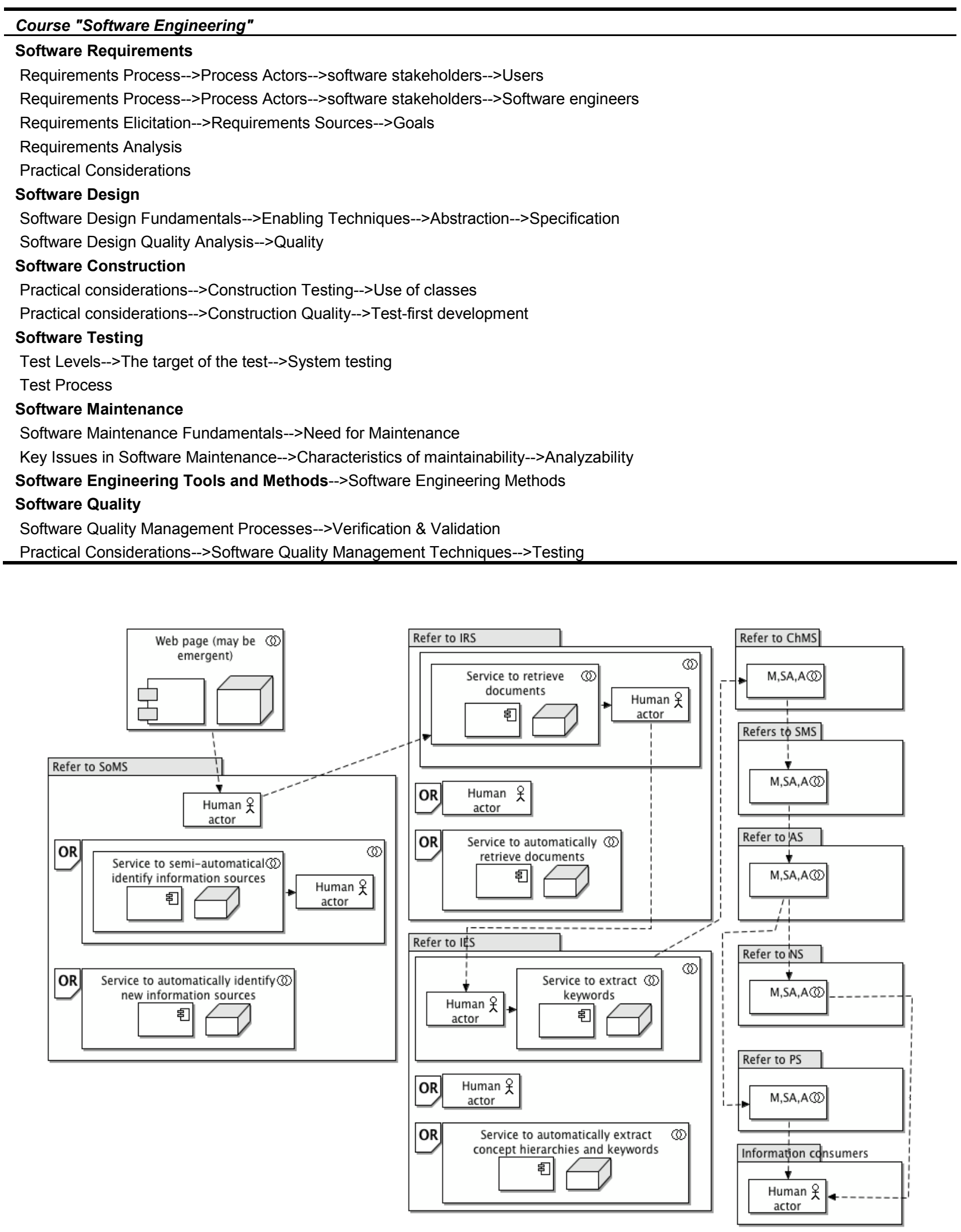

Figure 11. Variations in information logistics network

One can see that information in Figure 10 and Table 5 is suitable for automatic or semiautomatic processing while information represented in Table 4 could be useful for any mode of 
information processing. To make sure that the nodes of the network produce all relevant forms of information, it is necessary to control the correspondence between functional and morphological spaces of representation of information logistics. One of the ways how to achieve the control is (1) to choose a particular granularity of services in the functional space of representation and (2) to define for each node of chosen granularity the corresponding IPNs in the morphological space of representation. This will give an opportunity to decide which modes of processing are relevant to each node in the functional space of representation. When all modes of all functional nodes are known, the minimal number and the content of information flows between anticipated nodes can be identified.

In conceptual correspondence monitoring semi-automatic and automatic modes of information processing can foster the execution of overall sequence of monitoring information logistics by reducing time and effort. As a result we can faster obtain information about the conceptual correspondence between knowledge bodies and continuously keep track of its changes that may occur in the course of time. However, detection of conceptual correspondence requires involvement of human actors, which enriches the variety of information processing options to compare to fully manual or fully automatic, or strictly predefined semi-automatic information processing. This may cause emergent sequences in information logistics network in cases where the actual mode of functioning depends on non-structured circumstances. This refers to the internal information logistics of the monitoring node (Figure 2 and Figure 3). The external network of the conceptual correspondence monitoring node can also involve emergent nodes. One of such cases is shown in Figure 11 (upper node), where particular URLs may become unavailable and new URLs may appear constantly. Controlling compliance (correspondence) between the representations of information logistics in functional and in morphological spaces can help to deal with emergent nodes and be able to connect and disconnect nodes functioning in different modes of information processing.

\section{Conclusions}

The paper addresses information logistics for monitoring correspondence of conceptual structures. The conceptual correspondence is a non-numerical parameter and its monitoring requires human participation and can be enhanced by automatic processing of conceptual data such as texts, conceptual hierarchies, and ontologies. These features prescribe complex multimode information logistics for conceptual correspondence monitoring. The paper points to the following challenges of multimode information logistics:

- Necessity to handle the internal and external logistics of monitoring function

- Nested structure of information logistics network

- Several levels of granularity of functionality

- Several levels of granularity of performers

- Situation sensitive configurations of the network

- Emergent nodes and emergent configurations in the information logistics network

- Manual, semi-automatic, and automatic modes of information processing in the functional space of representation

The paper describes in detail the roots of above listed challenges. It suggests meeting these challenges by using interrelated representations of information logistics networks in the functional and morphological spaces of representation. It is important here that, in both spaces of representation, nested nodes of the networks, at lower levels of abstraction, can also be shown in the form of information logistics network. Similar approach is well known in the enterprise architecture modeling. In information logistics, however, more emphasis should be put on correspondence between information flows' configurations than it is currently common in the enterprise architecture modeling [30]. 
Commonly, the organizational roles in information logistics are considered as nodes of the network. The paper proposes an information processing node as the smallest granularity element in the morphological space of information logistics. Such approach provides a possibility to use finer configurations of the network, which, in turn, can give an opportunity to achieve higher flexibility of the network and is helpful in handling emergent configurations of the network.

The discussion in this paper is limited to (1) the description of approach and its illustration only (not the implementation) and (2) to the specific monitoring case where a monitoring parameter is a conceptual correspondence between particular conceptual structures.

Further work concerns adopting, adapting, and developing graph based algorithms for functional and morphological spaces of representations in order to perform management of information logistics for conceptual correspondence monitoring. Another direction of further work is to examine whether the approach proposed in this paper may be helpful for monitoring systems dealing with numerical values rather than with the conceptual structures.

\section{References}

[1] Princeton University, “About WordNet,” 2010. [Online]. Available: http://wordnet.princeton.edu./

[2] K. Osborne, R. Johnson, and T. Põder, Expert Oracle Exadata. Apress, 2011. Available: http://dx.doi.org/10.1007/978-1-4302-3393-0

[3] P. Hoverstadt, The fractal organization: creating sustainable organizations with the viable system model. Wiley. com, 2011.

[4] S. A. Chun, E. Portscher, and J. Geller, "Monitoring and updating regulations and policies for government services," in Electronic Government, Springer, 2005, pp. 81-92. Available: http://dx.doi.org/10.1007/11545156_8

[5] G. Papadopoulos and N. Bassiliades, "Monitoring conformance to the internal regulation of an MSc course using ontologies and rules," in Electronic Government and the Information Systems Perspective, Springer, 2011, pp. 212-226.

[6] J. Llinas, "A survey and analysis of frameworks and framework issues for information fusion applications," in Hybrid Artificial Intelligence Systems, Springer, 2010, pp. 14-23. Available: http://dx.doi.org/10.1007/978-3-642-13769-3_2

[7] K. Sandkuhl, A. Smirnov, and N. Shilov, "Information Logistics in Engineering Change Management: Integrating Demand Patterns and Recommendation Systems," in Workshops on Business Informatics Research, 2012, pp. 14-25. Available: http://dx.doi.org/10.1007/978-3-642-29231-6_2

[8] M. Apelkrans and A. Håkansson, "Information coordination using Meta-Agents in Information Logistics Processes," in Knowledge-Based Intelligent Information and Engineering Systems, 2008, pp. 788-798. Available: http://dx.doi.org/10.1007/978-3-540-85567-5_98

[9] L. Businska and M. Kirikova, "Knowledge dimension in business process modeling," in IS Olympics: Information Systems in a Diverse World, Springer, 2012, pp. 186-201. Available: http://dx.doi.org/10.1007/978-3-642-29749-6_13

[10] M. Kirikova and P. Rudzajs, "Multimode Information Logistics for Conceptual Correspondence Monitoring," in Proceedings of 5th Workshop on Information Logistics and Knowledge Supply (held in conjunction with BIR2012), 2012, pp. 31-42.

[11] P. Rudzajs and M. Kirikova, "IT Knowledge Requirements Identification In Organizational Networks : Cooperation Between Industrial Organizations And Universities," in 18th International Conference on Information Systems Development (ISD 2009), Springer, 2011, pp. 187-199. Available: http://dx.doi.org/10.1007/978-1-4419-7355-9_16

[12] Institute of Electrical and Electronics Engineers, "Guide to the Software Engineering Body of Knowledge." 2004. 
[13] P. Rudzajs and M. Kirikova, "Towards Monitoring Correspondence Between Education Demand and Offer," in 21st International Conference on Information Systems Development (ISD2012), Springer, 2013, pp. 467479. Available: http://dx.doi.org/10.1007/978-1-4614-7540-8_36

[14] P. de Alencar Silva and H. Weigand, "Enterprise monitoring ontology," in Conceptual Modeling--ER 2011, Springer, 2011, pp. 132-146. Available: http://dx.doi.org/10.1007/978-3-642-24606-7_11

[15] M. Dzbor and E. Motta, "Engineering and customizing ontologies,” in Ontology Management, Springer, pp. 25-57, 2008. Available: http://dx.doi.org/10.1007/978-0-387-69900-4_2

[16] R. Bendaoud, A. Napoli, and Y. Toussaint, "Formal concept analysis: A unified framework for building and refining ontologies," in Knowledge Engineering: Practice and Patterns, Springer, 2008, pp. 156-171. Available: http://dx.doi.org/10.1007/978-3-540-87696-0_16

[17] P. Wongthongtham and N. Kasisopha, "An ontology-based method for measurement of transferability and complexity of knowledge in multi-site software development environment," in Knowledge, Information, and Creativity Support Systems, Springer, 2011, pp. 238-252. Available: http://dx.doi.org/10.1007/978-3-64224788-0_22

[18] D. Ngo, Z. Bellahsene, and R. Coletta, “A Flexible System for Ontology Matching,” in CAiSE Forum 2011, vol. 107, 2011, pp. 73-80.

[19] N. Kiyavitskaya, N. Zeni, J. R. Cordy, L. Mich, and J. Mylopoulos, “Cerno: Light-weight tool support for semantic annotation of textual documents," Data Knowl. Eng., vol. 68, no. 12, 2009, pp. 1470-1492. Available: http://dx.doi.org/10.1016/j.datak.2009.07.012

[20] I. Birzniece and M. Kirikova, "Interactive Inductive Learning: Application in Domain of Education," Sci. J. Riga Tech. Univ. Comput. Sci. Appl. Comput. Syst., pp. 1-8 (in press), 2011.

[21] R. Coletta, E. Castanier, P. Valduriez, C. Frisch, D. Ngo, and Z. Bellahsene, "Public Data Integration with WebSmatch," in Proceedings WOD'12, 2012, vol. abs/1205.2. Available: http://dx.doi.org/10.1145/2422604.2422606

[22] J. Grundspenkis, "Structural modelling of complex technical systems in conditions of incomplete information: a review,” Mod. Asp. Manag. Sci., no. 1, 1997, pp. 111-135.

[23] J. Grundspenkis, "Reasoning supported by structural modelling," Lect. Notes Nord. Summer Sch. Intell. Des. Intell. Manuf. Intell. Manag. Jurmala, Latv. June 8-13, 1998.

[24] The Open Group, “ArchiMate 2.0 specification.” 2012.

[25] P. Rudzajs, "Towards Automated Education Demand-Offer Information Monitoring: the System's Architecture," in Selected Papers from Workshops and Doctoral Consortium of the International Conference on Perspectives in Business Informatics Research, BIR2011, Springer, 2012, pp. 252-265. Available: http://dx.doi.org/10.1007/978-3-642-29231-6_20

[26] S. Y. Yankovskiy, "Kontseptsii obshchey teorii informatsii”. vol. 5, 2001. [Online]. Available: http://www.inftech.webservis.ru/it/information/ar2.html,

[27] S. Brier and C. Joslyn, "What Does it Take to Produce Interpretation? Informational, Peircean and CodeSemiotic Views on Biosemiotics," Biosemiotics, Springer, 2013, pp. 143-159. Available: http://dx.doi.org/10.1007/s12304-012-9153-5

[28] M. Kirikova and J. Grundspenkis, "Types of knowledge and knowledge sources," Sci. Proc. Riga Tech. Univ. Ser. Comput. Sci. Appl. Comput. Syst. RTU, Riga, 2002, pp. 109-119.

[29] A. Rungsawang and N. Angkawattanawit, "Learnable topic-specific web crawler," J. Netw. Comput. Appl., vol. 28, no. 2, 2005, pp. 97-114. Available: http://dx.doi.org/10.1016/j.jnca.2004.01.001

[30] M. Lankhorst and H. van Drunen, "Enterprise Architecture Development and Modelling. Combining TOGAF and ArchiMate," 2007. 